\title{
The Relationship Between Heat Stress and Physical Workload with Worker's Hydration Status in Tirtonadi Bus Station Surakarta
}

\author{
Iwan Suryadi ${ }^{1 *}$, Istar Yuliadi $^{2}$, Seviana Rinawati $^{1}$, Siti Rachmawati ${ }^{3}$, Bekti Nugraheni ${ }^{4}$ \\ ${ }^{1}$ Department of Occupational Health and Safety, School of Vocational Study, Sebelas Maret \\ University \\ ${ }^{2}$ Department of Psychology, Faculty of Medicine, Sebelas Maret University \\ ${ }^{3}$ Department of Environmental Science, Faculty of Mathematics and Natural Sciences, Sebelas Maret \\ University \\ ${ }^{4}$ Student of Departement of Occupational Health and Safety, School of Vocational Study, Universitas \\ Sebelas Maret
}

\begin{abstract}
Terminal workers work with physical load activities every day and are in a hot work climate, which has the potential to experience status disturbances, potentially resulting in hydration problems. The purpose of the study was to analyze the relationship between Heat stress and Physical Workload and Hydration Status of Tirtonadi Bus StationWorkers in Surakarta. research design using observational analytic with a crosssectional approach. A sample of 48 people was taken by simple random sampling technique. Heat stress is measured by heat stress area, physical workload with SNI $726 / 2009$, and hydration status by urine specific gravity examination. the average heat stress measurement results amounted to $34.75^{\circ} \mathrm{C}$. the correlation between independent and dependent variables shows there is a significant relationship between heat stress and physical workload with hydration status with $\mathrm{p}$-value $=0,000$ and $\mathrm{r}=-0,799$, and $\mathrm{p}$ value $=0.028$ and $r=0.317$. Conclusion: There is a significant correlation between heat stress and hydration status, and there is a significant correlation between physical workload and the hydration status of workers at the Tirtonadi Surakata Terminal.
\end{abstract}

Keywords. Heat Stress, Physical Workload, Hydration Status.

\section{Background}

The current era of globalization, development throughout the world is developing rapidly. Increased transportation has an impact on the environment and humans. In the environment, for example, the existence of hot climate changes can affect the surrounding workforce [1].

\footnotetext{
*Corresponding author: iwansuryadi@staff.uns.ac.id
} 
Research by the American Consultant Institute says that there is an increase in the field of transportation every day in the world. In 2015 the number of bus transportation equipment was $2,420,917$ and in 2016 it rose to $2,486,898$ buses [2].

The physical workload is a natural burden by labor due to work performed [3]. Physical workload has a difference in each job. The working climate in Indonesia is tropical so that it has a temperature of $24{ }^{\circ} \mathrm{C}$ and $26^{\circ} \mathrm{C}$, Indonesian people who get a hot heat stress result in a disturbed balance of bodily functions [4].

Research conducted by The Indonesia Regional Hydration Study (THIRS) in 2010 conducted in various major cities in Indonesia, amounting to $42.5 \%$ of the population of Indonesia (19 - 49 years) affected by hydration and $49.5 \%$ hydration at vulnerable ages (1518 years old) [5]. Workers at the terminal can also experience the risk of lack of bodily fluids due to insufficient water replacement and added radiation from the heat of the running bus engine. The balance of body fluids for body metabolism is called hydration [6]. Previous research conducted by Puspita (2015) at PT X in Sidoarjo stated that there is a relationship between heat stress and workload on the level of worker hydration [7].

Tirtonadi Bus StationSurakarta is the largest terminal in the city of Surakarta and received the title of the best pilot terminal in Indonesia. The number of buses entering the terminal every day is 1,500 bus fleets. For traffic officers, security officers, and Tirtonadi Bus Stationcleaners have a high risk of exposure [8].

Based on the initial survey conducted by the researchers produced $33.76^{\circ} \mathrm{C}$ and $35.85^{\circ}$ C. The initial survey of physical workload measurement results, which are 3 workers, light workload, and 6 workers, moderate workload. Results The initial hydration survey carried out resulted in 10 workers experiencing hydration in the well-hydrated category.

\section{Subjects and methods}

This research is an observational analytic study with cross-sectional study design. This research was conducted at Tirtonadi Terminal, Surakarta. The population in this study amounted to 54 workers, then using a random sampling method, the results obtained were 48 respondents with a vulnerable age of 18-64 years (productive age). The independent variables in this study are the heat stress and physical workload. The dependent variable is the hydration status. Measurement of heat stress variable instruments was measured using a Heat Stress Area Tool, Physical workload research instrument based on SNI 7269 of 2009, namely by observing and analyzing work based on the level of calorie expenditure hydration status using urine specific gravity laboratory tests.

Data were analyzed by univariate analysis to determine the distribution of respondent characteristics and bivariate analysis to determine the correlation between work climate, and physical workload with hydration status.

\section{Results}

\subsection{Univariate analysis}

Based on research conducted, obtained the tendency of the following results of respondents: 
Table 1. Frequency Tendency of Respondents in Tirtonadi Bus StationSurakarta

\begin{tabular}{|l|l|l|l|l|}
\hline Characteristics & $\mathrm{n}$ & Mean & Min & Max \\
\hline Age & 48 & 48,37 & 26 & 64 \\
\hline Work Period & 48 & 18,87 & 1 & 45 \\
\hline Break & 48 & 60,4 & 25 & 80 \\
\hline
\end{tabular}

Sources: Primary Data, 2018

Based on table 1 of the tendency distribution above, data obtained by workers at Tirtonadi Bus Station have the youngest age at 26 years and the oldest age at 64 years.

The tenure of 48 Tirtonadi Bus Stationrespondents has the least working period of working for 1 year and the longest working for 45 years. The average Tirtonadi Bus Stationworker worked for 19 years.

Tirtonadi Bus StationCompany has provided 60 minutes of rest time at $12.00-13.00$ WIB. The average worker rests for 60 minutes. Based on the results of the survey there are Tirtonadi Bus Stationworkers who rest only 25 minutes and there are workers.

Table 2. Average Wet and Ball Temperature Index (ISBB) values at Tirtonadi Bus Station Surakarta.

\begin{tabular}{|l|l|c|c|}
\hline No & Location & Time & ISBB $\left({ }^{\circ} \mathrm{C}\right)$ \\
\hline \multirow{3}{*}{1.} & Point 1 East Door & 08.10 & 33,9 \\
\cline { 3 - 4 } & & 11.20 & 35,4 \\
\cline { 3 - 4 } & & 14.10 & 35,8 \\
\cline { 2 - 4 } & Result & & 35,0 \\
\hline \multirow{2}{*}{2.} & Point 2 West Door & 09.15 & 33,1 \\
\cline { 3 - 4 } & & 11.50 & 35,0 \\
\cline { 3 - 4 } & & 14.30 & 35,5 \\
\cline { 2 - 4 } & Result & & 34,5 \\
\hline
\end{tabular}

Sources: Primary Data, 2018

Table 2. Based on the measurements made, it is found out that the working climate in the Tirtonadi Bus Station has a Wet and Ball Temperature Index (ISBB) conducted at the East and West Doors and the final result is the working climate of the Tirtonadi Bus Station is $34.5^{\circ} \mathrm{C}$.

Table 2 results explain the assessment of the workload on the workforce of $12.5 \%$ experiencing a mild category of physical workload. 77.1\% of Tirtonadi Bus Stationworkers experience medium category physical workloads and $10.4 \%$ experience heavy category physical workloads.

Table 3. Frequency Distribution of Physical Workload

\begin{tabular}{|l|c|l|}
\hline .Phycical Workload & $\mathrm{n}$ & $\%$ \\
\hline Lightweight $(100-200 \mathrm{kkal} / \mathrm{jam})$ & 6 & 12,5 \\
\hline Medium $(>200-350 \mathrm{kkal} / \mathrm{jam})$ & 37 & 77,1 \\
\hline Weight $(>350-500 \mathrm{kkal} / \mathrm{jam})$ & 5 & 10,4 \\
\hline Total & 48 & 100 \\
\hline
\end{tabular}

Sources: Primary Data, 2018 
Tabel 4. Hydration Status Measurement Results

\begin{tabular}{|l|l|l|}
\hline Hidration Status & $\mathrm{n}$ & $\mathbf{( \% )}$ \\
\hline Well Hydrated & 10 & 20,8 \\
\hline Mildly Hydrated & 20 & 41,7 \\
\hline Moderately Hydrated & 18 & 37,5 \\
\hline Dehydrated & 0 & 0 \\
\hline Clinically Dehydrated & 0 & 0 \\
\hline
\end{tabular}

Sources: Primary Data, 2018

Based on table 4 , the hydration status was assessed from the results of urine specific gravity measurements showing that $20.8 \%$ of Tirtonadi Bus Stationworkers experienced Well Hydrated, then $41.7 \%$ of workers experienced Mildly Hydrated and the remaining $37.5 \%$ of workers experienced Moderately Hydrated.

\subsection{Bivariate analysis}

\subsubsection{Correlation of Heat stress with Hydration Status Burden}

The test used is the Spearman Test like the following table:

Table 5. Results of the Analysis of the Relationship between Heat stress and Hydration Status

\begin{tabular}{|c|c|c|c|}
\hline Dependent Variable & Independent Variable & $\mathrm{p}$-value & $\mathrm{r}$ \\
\hline Work Climate & Hydration status & 0,000 & $-0,799$ \\
\hline
\end{tabular}

Based on table 4 of the Spearman Test it is known that the significance value is p-value 0,000 . Because the significance value of 0,000 is smaller than 0.005 , it means that there is a significant (meaning) relationship between heat stress and hydration status. Furthermore, the correlation strength is -0.799 , which means strong strength. The direction of the relationship between heat stress and hydration status has a negative value (-) which means that if the heat stress increases, the hydration status will get worse.

\subsubsection{Test the Relationship of Physical Workload with Hydration Status}

The test used is the Spearman Test like the following table:

Table 6. Spearman Test Relationship between Physical Workload and Hydration Status

\begin{tabular}{|c|c|c|c|}
\hline Dependent Variable & Independent Variable & p-value & $\mathrm{r}$ \\
\hline Physical Workload & Hydration Status & 0,028 & 0,317 \\
\hline
\end{tabular}

Based on table 5, the Spearman test shows the significant value between physical workload and hydration status, which is p-value 0.028 . Because the significance value of 0.028 is smaller than 0.05 , it means that there is a significant (meaning) relationship between physical workload and hydration status. the strength of the relationship between physical workload and hydration status is 0.317 , which means a weak relationship between physical workload and hydration status. And for the direction of the relationship between physical workload and hydration status has a positive value $(+)$, so that if the physical workload increases, the hydration status increases. 


\section{4. .Discussion}

Based on data obtained by workers at the Tirtonadi Terminal, Surakarta is known to have a more advanced age than younger workers. This age difference can cause an effect on one's hydration status.

Age affects the physiological changes in the workforce and is influenced by the amount of fluid intake and the balance of the body's systems. This change is about decreasing fatfree mass together with decreasing total body fluids and decreasing thirst sensation so that water consumption will decrease [9]. Workers at Tirtonadi Bus Station have a minimum working period of 1 year and a maximum of 45 years. The average Tirtonadi Bus Stationworker worked for 19 years. The longer a person works, the more likely it is to be exposed to health risks. This is because the longer they work the worker will be exposed to the risk of continuous danger every time they work every day [4].

The break time of workers at the Tirtonadi Bus Station has a difference because some workers deliberately extend their break times and some workers have rested even though they have not entered break time. But if the worker breaks less than 30 minutes or less, it will have an impact on the body of the workforce and be able to cause interference with the worker's body. Disorders that occur such as loss of concentration, work fatigue, and other risks [4].

The result of the working climate of the Tirtonadi Bus Station is $34.75^{\circ} \mathrm{C}$. This is certainly a working climate in the Tirtonadi Bus Station that has exceeded the threshold value allowed by Permenakertrans No. Per. 5 / MEN / 2018 concerning Occupational Safety and Health in the Work Environment because the 8-hour work standard has a threshold value of $28.0^{\circ} \mathrm{C}$ for moderate workloads [10].

Workers who are in a heat stress above the threshold value will not be able to affect working conditions. This is a natural and physiological response and the reason for the company providing a normal work climate. The body needs to work optimally in a normal heat stress [11].

Tirtonadi Bus Station there are still workers who fall into the category of moderate workloads and heavy physical workloads. The physical workload can result in sweat expenditure, suppression of sweat expenditure related to the metabolic system, and excreted through the skin. Evaporated sweat will increase the osmotic pressure of the skin. Sweat contains a variety of salt, and perspiration will result in loss of salt. this can increase the risk of health problems of worker 12].

Hydration status in Tirtonadi Bus StationWorkers in Surakarta mostly experienced a reduction in body fluids compared to the addition of liquid in the body resulting in an imbalance of fluids in the body [13].

In this study, the correlation strength between heat stress and hydration status is 0.799 , which means it has a strong correlation strength. The strength of the correlation of heat stress with the status of hydration is strong because workers in the Tirtonadi Bus Stationary exposed to a hot heat stress that exceeds the allowable threshold value.

This is by Beaty \& Kauwell's theory which states that there is a relationship between heat stress and hydration status. This is because the working climate mechanism that has indicators of wet temperature and ball temperature consisting of globe temperature, dry bulb, and wet bulb if the value exceeds the threshold value will cause hydration status [12].

This study the relationship of the physical workload with hydration status has a positively correlated strength. In this case, it means that there is a weak relationship between physical workload and hydration status. And a positive correlation means that if the physical workload increases, the hydration status increases. This is by research [13]. 
The strength of correlation has a weak value because workers at Tirtonadi Bus Station in Surakarta have different physical workload values, there are still inappropriate breaks and there are still workers who experience a lack of fluids.

This study is by the theory of that the physical workload is related to the energy use of a person who performs the physical activity. This is associated with the body's metabolic rate [14]

\section{Conclusions and suggestions}

The heat stress measurement results at Tirtonadi Bus Stationary $34.75^{\circ} \mathrm{C}$ or exceeding the permitted Threshold Value. The measurement results of the physical workload of Workers at Tirtonadi Bus Stationary 12.5\% light physical workload, 77.1\% moderate physical workload, $10.4 \%$ physical workload. There is a relationship between the heat stress and hydration status of workers at the Tirtonadi Terminal. There is a relationship between physical workload and hydration status in Tirtonadi Bus Stationworkers will increase. Companies should install urine color level indications that show the hydration status category, especially in the bathroom area, making it easier for workers to know the condition of their hydration status.

Companies should improve the circulation system (exhaust fan) and carry out periodic heat stress measurements to find out the average temperature in the workplace to avoid exposure to bad working climate. Consume enough glass of water (250 ml) every 20-30 minutes or the total amount of water consumed by workers at least 2 liters per day to avoid lack of fluids, exposure to work climate, and improve body condition from physical workload activities.

\section{References}

1. S, Moeljosoedarmo. Industrial Hygiene. FKUI Publisher Center, (2008)

2. The Central Statistics Agency (BPS) is accessed from http://www.bps.go.id/, accessed on November 1, 2018 at 20.20 WIB.

3. Indonesian National Standard number 726. 2009. Workload Assessment based on Calorie requirements according to energy expenditure. National Standardization Agency,(2009)

4. P. K Suma'mur. Company Hygiene and Work Safety. CV Haji Mas Agug Seto, (2014)

5. B Murray. Hydration and Physical performance. Hydration and Health Proportion. ILSI North America, (2006)

6. Oppliger. Jrnl of Hmn Kntcs, pp. 15: 231-233.(2008)

7. A. D. Puspita, , Airlangga University, (2015)

8. The Directorate General of Land Transportation is accessed at http://ppid.dephub.go.id/, accessed on 2 November 2018 at 07.00.

9. A., Shadrina, University of Indonesia, (2012)

10. Indonesian Ministry of Manpower. Regulation of the Minister of Manpower and Transmigration No.5 Year 2018. About Work Safety and Health Work Environment, (2018):

11. Marcos, A., Manonelles, P. \& Palacios, N.,. Physical Activity, Hydration and Health. Nutrition Hospitalaria, ( 2014) Volume VI.

12. G Bates. \& J Schneider,., Journal of Occupational Medicine and Toxicology, (2008) Pp. 3 (21): 4-5.

13. Beatty, J. \& Kauwell, G. P. A. Hydration in Hot Working Environments.( 2014) 
14. I Rachmatiani, I Suryadibrata, S Nurlita,. \& A Lisswardi, Energy Metaboslime and Thermogulation, (2013) 